\title{
Article
}

\section{Poly (ether imide sulfone) membranes from solutions in ionic liquids}

\author{
Dooli Kim, and Suzana P. Nunes
}

Ind. Eng. Chem. Res., Just Accepted Manuscript • DOI: 10.1021/acs.iecr.7b03581 • Publication Date (Web): 20 Nov 2017

Downloaded from http://pubs.acs.org on December 4, 2017

\section{Just Accepted}

"Just Accepted" manuscripts have been peer-reviewed and accepted for publication. They are posted online prior to technical editing, formatting for publication and author proofing. The American Chemical Society provides "Just Accepted" as a free service to the research community to expedite the dissemination of scientific material as soon as possible after acceptance. "Just Accepted" manuscripts appear in full in PDF format accompanied by an HTML abstract. "Just Accepted" manuscripts have been fully peer reviewed, but should not be considered the official version of record. They are accessible to all readers and citable by the Digital Object Identifier (DOI®). "Just Accepted" is an optional service offered to authors. Therefore, the "Just Accepted" Web site may not include all articles that will be published in the journal. After a manuscript is technically edited and formatted, it will be removed from the "Just Accepted" Web site and published as an ASAP article. Note that technical editing may introduce minor changes to the manuscript text and/or graphics which could affect content, and all legal disclaimers and ethical guidelines that apply to the journal pertain. ACS cannot be held responsible for errors or consequences arising from the use of information contained in these "Just Accepted" manuscripts. 


\section{Introduction}

Membrane technology has been used in various fields such as biomedical separations ${ }^{1-4}$, desalination ${ }^{5}$, wastewater treatment ${ }^{6}$, and energy conversion ${ }^{7-9}$. It is playing a crucial role in fulfilling a sustainable process on producing water and separating, recycling, and reuse of wastes with less energy consumption and less cost, comparing with other traditional water production processes ${ }^{10-14}$. However, there are concerns that the sustainability can only be completely achieved if the membrane manufacture itself will be performed with less toxic and alternative chemicals to solvents, such as dimethylformamide (DMF); 1-methyl-2-pyrrolidone (NMP); and N, Ndimethylacetamide (DMAc) ${ }^{15-18}$.

Ionic liquids can be considered as green solvents ${ }^{19}$ from a perspective of no generation of harmful volatile organic chemicals (VOCs) ${ }^{20}$. Research on ionic liquids as green solvents for polymer dissolution has increased, especially since the confirmation that they can dissolve biopolymers, such as cellulose ${ }^{21-23}$ and chitin ${ }^{24}$, which are hardly dissolved in any other organic solvent. They have been reported for production of biofuel and for membrane fabrication ${ }^{25-27}$. The use of ionic liquids to dissolve synthetic polymers with sulfone or imide groups and their use for membrane fabrication have been gradually reported ${ }^{28,29}$. Ionic liquids have been also used as additives in polymer solutions ${ }^{30,31}$.

EXTEM $^{\mathrm{TM}}$ is a commercialized petroleum based polymer, which is known for excellent mechanical and chemical stability. It is structurally composed of etherimide and sulfone groups. It has been used for membrane fabrication, e.g. Xia et al. ${ }^{32}$ and Peng et al. ${ }^{33}$ as hollow fiber membranes for gas separation. Jalal et al. ${ }^{34}$ fabricated EXTEM $^{\mathrm{TM}}$ ultrafiltration membranes for liquid separation. Recently Mazinani et al. ${ }^{35}$ investigated the phase separation of EXTEM ${ }^{\mathrm{TM}}$, being more difficult to dissolve than other polysulfones. The membranes however were fabricated from NMP and DMF which are good solvents, but are considered as relatively toxic.

In this study, we propose the use of ionic liquids for EXTEM $^{\mathrm{TM}}$ solubilization and membrane preparation. Interestingly, we found out that high quantity of EXTEM ${ }^{\mathrm{TM}}$ can be dissolved in different ionic liquids: 1-ethyl-3methylimidalzolium thiocyanate ([EMIM]SCN), 1-butyl-3methylimidalzolium thiocyanate ([BMIM]SCN), and 1-ethyl3-methylimidalzolium acetate ([EMIM]OAc). This has not been reported before. For better optimization we investigated the solution thermodynamics of the EXTEM ${ }^{\mathrm{TM}} /$ ionic liquids systems and kinetic aspects of phase separation. Membranes were prepared and characterized. This study will contribute to find alternative methods for greener membrane fabrication.

\section{Methodology}

\subsection{Materials}

Poly (ether imide sulfone), EXTEM ${ }^{\mathrm{TM}}$ XH1005 was kindly provided by SABIC. The average molecular weight of $85 \mathrm{~kg}$ $\mathrm{mol}^{-1}$ was estimated by viscosity measurements, using the Mark-Houwink equation, as shown in Table 1S. [EMIM]SCN ( $\geq 95.0 \%$ ), [BMIM] SCN ( $\geq 95.0 \%)$, and DMF $(\geq 99.0 \%)$ were purchased from Sigma-Aldrich. The structures of EXTEM ${ }^{\mathrm{TM}}$ and ionic liquids are shown in Figure 1. Polyethylene glycol (PEG) and polyethyleneoxide (PEO) (Sigma-Aldrich), with molecular weight of $0.3,1.5,6,10$, and $35 \mathrm{~kg} \mathrm{~mol}^{-1}$, were used for rejection evaluation and determination of the molecular weight cut-off (MWCO). Deoxyribonucleic acid (DNA, 3229 and $6441 \mathrm{~g} \mathrm{~mol}^{-1}$ composed of adenine and guanine), bovine serum albumin $\left(B S A, \sim 66 \mathrm{~kg} \mathrm{~mol}^{-1}\right)$, and $\gamma$-globulin $(\sim 140 \mathrm{~kg}$ $\mathrm{mol}^{-1}$ ) were supplied from Sigma-Aldrich. 


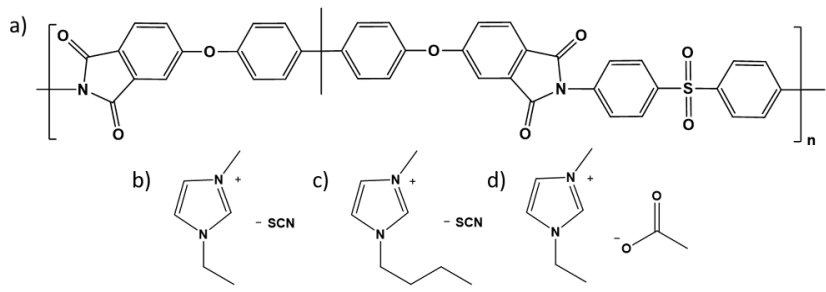

Figure 1. Chemical structures of (a) EXTEMTM, (b) [EMIM]SCN, (c) [BMIM]SCN, and (d) [EMIM]OAc.

\subsection{Polymer solution thermodynamics}

For non-charged organic solvents $\Delta G_{m}$ can be calculated from solubility parameters $(\delta)$ and Flory-Huggins parameters $(\chi)$, which mainly take into consideration the interaction contributions of van der Waals forces, polarity and hydrogen bonds. This estimation does not count coulombic interactions, which are important in the case of ionic liquids, but can give guidance to predict the miscibility of a polymer/solvent mixture ${ }^{36}$. If $\Delta G_{m}$ is negative, the polymer solubility is favored in the specific solvent. In contrast, if $\Delta G_{m}$ is significantly higher than zero, the mixture is unlikely to be homogenous. According to the Flory-Huggins theory, $\Delta G_{m}$ can be estimated by the following equation ${ }^{37}$ :

$$
\frac{\Delta \mathrm{G}_{\mathrm{m}}}{\mathrm{N}_{\mathrm{A}}}=\mathrm{kT}\left[\chi \emptyset_{1} \emptyset_{2}+\frac{\emptyset_{1}}{\mathrm{X}_{1}} \ln \emptyset_{1}+\frac{\emptyset_{2}}{\mathrm{X}_{2}} \ln \emptyset_{2}\right]
$$

where $k$ is the Boltzmann constant, $T$ is the absolute temperature $(\mathrm{K})$, and $\phi_{l}$ and $x_{i}$ are the volume fraction and number of segments of the $\mathrm{i}^{\text {th }}$ component, respectively. $\chi$ is the FloryHuggins parameter, which can be calculated from equation 2:

$\chi_{\mathrm{ij}}=\frac{\mathrm{V}_{\mathrm{i}} \delta_{i}-\delta_{\mathrm{j}}{ }^{2}}{\mathrm{RT}}+0.34$

where $V_{i}$ is the molar volume of the solvent $\left(\mathrm{cm}^{3} \mathrm{~mol}^{-1}\right), R$ is the ideal gas constant $\left(\mathrm{cm}^{3} \mathrm{MPa} \mathrm{K}^{-1} \mathrm{~mol}^{-1}\right)$. The value of 0.34 is an empirical constant absent in the original theory and later introduced for polymer systems ${ }^{38-41} . \delta$ is the solubility parameter of the solvent $i$ and polymer $j\left(\mathrm{MPa}^{1 / 2}\right)$.

Few studies have attempted to calculate the $\delta$ of ionic liquids ${ }^{42-46}$. Here the $\delta$ values of EXTEM ${ }^{\mathrm{TM}}$, [EMIM]SCN, and [BMIM]SCN were determined using the HSPiP ${ }^{40}$ software, based on miscibility tests with different solvents. The dispersive $\left(\delta_{\mathrm{D}}\right)$, dipole-dipole $\left(\delta_{\mathrm{p}}\right)$, and hydrogen bonding $\left(\delta_{\mathrm{H}}\right)$ contributions to the Hansen solubility parameters ${ }^{40}$ were computed by the software. The total solubility parameters $(\delta)$ were then calculated by the following equation 3 :

$$
\delta^{2}=\delta_{\mathrm{D}}^{2}+\delta_{\mathrm{P}}^{2}+\delta_{\mathrm{H}}^{2}
$$

The $\delta$ contributions for [EMIM]OAc were previously reported 27,28

\subsection{Polymer solutions characterization}

In the cases of homogenous polymer solutions, larger polymer coils indicate higher solubility. From the intrinsic viscosity $([\eta])$, the size of the polymer coils was estimated. To measure $[\eta]$, different polymer solutions $(0.05,0.1,0.2$, and $0.3 \mathrm{wt} \%$ EXTEM $^{\mathrm{TM}}$ in [EMIM]OAc, [EMIM]SCN, [BMIM]SCN, and DMF) were prepared and their viscosities were measured us- ing an Ubbelohde viscometer (Lauda iVisc). $[\eta]$ can be calculated by equation 4 :

$$
[\eta]=\lim _{\mathrm{c} \rightarrow \mathrm{o}}\left(\frac{\eta_{r e l}-1}{c}\right)=\lim _{\mathrm{c} \rightarrow \mathrm{o}} \eta_{\text {red }}
$$

where $\eta_{\text {rel }}$ is the relative viscosity (defined as $\eta_{\text {rel }}=$ dynamic viscosity / solvent viscosity), $\eta_{\text {red }}$ is the reduced viscosity (defined as $\left.\eta_{\text {red }}=\left(\eta_{\text {rel }}-1\right) / C\right)$, and $\mathrm{C}$ is the concentration of the polymer solution.

From $[\eta]$, the radius of gyration, $R_{g}$, can be calculated. The entanglement concentration $\left(C^{*}\right)$ is estimated from the inverse of $[\eta]$ (equation 5):

$C^{*}=1 /[\eta]$

$C^{*}$ is related to $R_{g}$ by equation 6 :

$$
C^{*}=\frac{M}{\frac{4}{3} \pi N_{A} R_{g}^{3}}
$$

where $M$ is the molecular weight of EXTEM $^{\mathrm{TM}}, N_{A}$ is the Avogadro number $\left(6.022 \times 10^{23} \mathrm{~mol}^{-1}\right)$, respectively. From $R_{g}$, the hydrodynamic radius $\left(R_{h}\right)$ and diameter $\left(D_{h}\right)$ can be estimated $\left(R_{h}=0.77 R_{g}\right)^{47} . D_{h}$ calculated from $[\eta]$ was compared to those obtained by transmission electron microscopy (TEM) using a Technai 12 FEI microscope operated at $120 \mathrm{kV}$. For that a droplet of diluted EXTEM ${ }^{\mathrm{TM}}$ solutions $(0.1 \mathrm{wt} \%)$ in different solvents was placed on a carbon-coated copper grid and the excess was removed. The samples were stained with ruthenium tetroxide $\left(\mathrm{RuO}_{4}\right)$ vapor for 3 hours.

The rheology of EXTEM ${ }^{\mathrm{TM}}$ solutions was investigated using a AR1500ex Rheometer, TA Instruments, at shear rate of $10 \mathrm{~s}^{-1}$ in the temperature range of 25 to $90{ }^{\circ} \mathrm{C}$.

Phase diagrams of a polymer/solvent/non-solvent system were estimated by cloud point tests. EXTEM ${ }^{\mathrm{TM}}$ solutions were prepared with different compositions. Their cloud points were determined by adding water as non-solvent at room temperature until turbidity was observed. The amount of EXTEM ${ }^{\mathrm{TM}}$, solvents, and water needed to reach each cloud point was plotted in ternary diagrams.

The phase separation kinetics was studied by light transmittance experiments. EXTEM ${ }^{\mathrm{TM}}$ solutions were cast on a glass plate with the solution gap of $250 \mu \mathrm{m}$ and then immediately immersed in water as non-solvent. The change of light transmittance as a function of time was monitored at $600 \mathrm{~nm}$ (water has no absorbance peak at this wavelength) ${ }^{26}$ using a Cary 5000 UV-Vis-NIR, Agilent. The relative light transmittance $\left(T_{r}\right)$ was determined by equation $7^{27,28}$.

$\operatorname{Tr}=\frac{(\mathrm{T}-\mathrm{Tmin})}{(\operatorname{Tmax}-\mathrm{Tmin})} \times 100 \%$

where $T_{\min }, T_{\max }$ and $T$ are the minimum, maximum, and the raw transmittance at specific time, respectively.

\subsection{Membrane fabrication and characterization}

All solutions were cast on non-woven with a doctor blade gap of $250 \mu \mathrm{m}$ and with the controlled temperature of $70{ }^{\circ} \mathrm{C}$. The cast solutions were immersed in a deionized water bath at room temperature to induce phase separation and kept in water for a day to eliminate any residual solvents.

The membrane morphologies were observed by field emission scanning electron microscopy (FESEM) (FEI Quanta 200, Quanta 600, and Nova Nano FESEM). First, membrane sam- 
1

2

3

4

5

6

7

8

9 ples were prepared by freeze-drying to avoid pore collapse. The membrane samples were fractured in liquid nitrogen, and then coated with iridium for cross-sectional images.

The water permeance was measured by filtering water through the membranes and then calculated by equation 8 :

$$
\text { Water permeance }=Q \cdot A^{-1} \cdot \Delta P^{-1}
$$

where $Q$ is the water flow rate $(\mathrm{L} / \mathrm{h}), A$ is the effective membrane area $\left(\mathrm{m}^{2}\right)$, and $\Delta P$ is the applied pressure (bar).

Pore size, pore distribution, and MWCO were investigated by filtration tests with neutral solutes PEG and PEO, which are composed of molecular weight of $0.3,1.5,6,10$, and $35 \mathrm{~kg}$ $\mathrm{mol}^{-1}$. The rejection was evaluated by equation 9 :

$$
\mathrm{R}(\%)=\left(1-\frac{\text { Cperm }}{\text { Cfeed }}\right) \times 100 \%
$$

where $C_{\text {perm }}$ and $C_{\text {feed }}$ are the concentrations of the permeate and feed solutions, respectively, which was analyzed by gel permeation chromatography (GPC) with PL aquagel-OH 40 and 60 columns (1260 infinity GPC/SEC, Agilent technologies).

The solute Stokes radius (in $\mathrm{cm}$ ), $r$, was calculated by equation 10 and $11^{48,49}$.

\section{For PEG}

$r=16.73 \times 10^{-10} M^{0.557}$

For PEO

$r=10.44 \times 10^{-10} M^{0.587}$

where $M$ is the molecular weight (in $\mathrm{g} / \mathrm{mole}$ or Da) of PEG or PEO. The relation between the solute diameter $(d=2 r)$ and its rejection is shown in the equation 12 and the pore size probability of membranes is expressed by the equation 13 .

$\mathrm{F}(\mathrm{R})=\mathrm{A}+\mathrm{B}(\ln \mathrm{d})$

$\frac{\mathrm{dR}(\mathrm{dp})}{\mathrm{d}(\mathrm{dp})}=\frac{1}{\mathrm{dp} \ln \sigma p \sqrt{2 \pi}} \exp \left[-\frac{(\ln \mathrm{dp}-\ln \mu \mathrm{p}) 2}{2(\ln \sigma \mathrm{p}) 2}\right]$

where $\mu_{p}$ is the mean effective pore diameter at $R=50 \%$. $\sigma_{p}$ is the geometric standard deviation, defined as the ratio of $d$ values at $R=84.13$ and $50 \%$ by neglecting the steric and hydrodynamic hindrance effects ${ }^{49}$ and ignoring the deformation of macromolecules under pressure and shear rate in the solution ${ }^{50}$. The molecular weight cut-off (MWCO, $R=90 \%$ ) was calculated by equation 12 .

\subsection{Proteins and DNA separation}

The water permeance and rejection of all membranes were examined by filtration of DNA, BSA, and $\gamma$-globulin solutions $\left(1 \mathrm{~g} \mathrm{~mL}^{-1}\right)$ through the membranes, using a dead-end ultrafiltration set-up (Amicon cell). The feed solutions for BSA, and $\gamma$ globulin were prepared in the phosphate buffered saline solution $(20 \mathrm{mM})$. Primary DNA with designed molecular weights 3220 and $6440 \mathrm{~g} \mathrm{~mol}^{-1}$ were dissolved in water and used as feed solutions. Their rejections were calculated by equation 6 based on their permeate and feed concentrations, which were analyzed by a UV spectrometer at $260 \mathrm{~nm}$ (Thermo scientific, Nanodrop 2000c).

\section{Results}

3.1. Binary polymer solutions in ionic liquids

The difference between EXTEM ${ }^{\mathrm{TM}}$ and ionic liquid solubility parameters was taken as a first indication of potential solubility. Table 1 shows the solubility parameters of all components used in this study and the polymer-solvent parameter difference. The solubility of EXTEM ${ }^{\mathrm{TM}}$ in different solvents would then decrease in the following order: DMF $>$ [BMIM]SCN $>$ $[$ EMIM]OAc $>[$ EMIM] SCN.

Table 1. Solubility parameters of the polymer and solvents

\begin{tabular}{lcccll}
\hline & $\delta_{D}$ & $\delta_{P}$ & $\delta_{H}$ & $\begin{array}{l}\delta \\
{\left[\mathrm{MPa}^{1 / 2}\right]}\end{array}$ & $\begin{array}{l}\mid \delta_{\text {EXTEM }^{\mathrm{TM}}-} \\
\delta_{\text {solvent }} \mid\end{array}$ \\
\hline EXTEM $^{\mathrm{TM}^{a}}$ & 21 & 10.9 & 10.6 & 26 & - \\
[EMIM]SCN $^{a}$ & 22.7 & 19.1 & 15.6 & 33.5 & 7.5 \\
{$\left[\right.$ BMIM]SCN $^{a}$} & 19.5 & 17.1 & 12.6 & 28.9 & 2.9 \\
[EMIM]OAc $^{a}$ & 22.2 & 15.9 & 16.9 & 32.1 & 6.1 \\
DMF $^{b}$ & 17.4 & 13.7 & 11.3 & 24.9 & 1.1 \\
Water $^{b}$ & 15.5 & 16 & 42.3 & 47.8 & \\
\hline
\end{tabular}

used in this study.

${ }^{a}$ Calculated using HSPiP and ${ }^{\mathrm{b}}$ from Ref. ${ }^{40}$

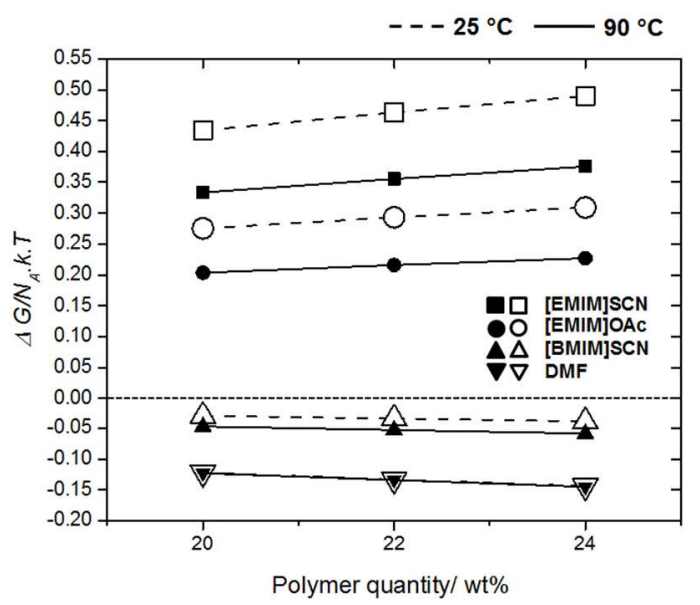

Figure 2. $\Delta G$ estimation for EXTEM ${ }^{\mathrm{TM}}$ in different ionic liquids at 25 (dash lines) and $90{ }^{\circ} \mathrm{C}$ (solid lines).

Values of Gibbs free energy of mixing $(\Delta G)$, which are calculated using Flory-Huggins parameters estimated from solubility parameters, are illustrated in Figure 2. Although the strong coulombic interactions involved in solutions containing ionic liquids are not completely taken into account by FloryHuggins, the values of $\Delta G$ were taken as a guidance for solubility. Values close to zero or below are an indication of homogeneous systems. The $\Delta G$ for EXTEM ${ }^{\mathrm{TM}} /[\mathrm{BMIM}] \mathrm{SCN}$ and 
DMF was below zero. It denotes that the EXTEMTM solutions in [BMIM]SCN and DMF are thermodynamically stable and homogenous. In case of EXTEM ${ }^{\mathrm{TM}} /[\mathrm{EMIM}] \mathrm{OAc}$ and EXTEM $^{\mathrm{TM}} /[\mathrm{EMIM}] \mathrm{SCN}$, the values of $\Delta G$ were positive, but not far from zero, still enough for solubilization. EXTEM ${ }^{\mathrm{TM}}$ therefore seems to have weaker interactions with [EMIM]OAc and [EMIM]SCN than with DMF and [BMIM]SCN. Furthermore, it is important to note that high temperature is critical to dissolve polymers in the investigated ionic liquids. By increasing the temperature from 25 to $90{ }^{\circ} \mathrm{C}$, all $\Delta G$ values slightly decreased, following equation 2 for $\chi$. As the temperature increases, $\chi$ decreases and the interaction between polymers and solvents increases (lower $\Delta G$ ).

The intrinsic viscosity $([\eta\rceil)$ leads to the calculation of molecular weight and coil size of polymers in solution. The $[\eta]$ values for EXTEM ${ }^{\mathrm{TM}}$ in different solvents are shown in Table 1S and Table 2. The values of $[\eta]$ for EXTEM ${ }^{\mathrm{TM}}$ decreases in the following order: [BMIM]SCN $>$ [EMIM]OAc $>$ DMF $>$ [EMIM]SCN and the hydrodynamic diameter $\left(D_{h}\right)$ calculated from $[\eta]$ was consistent with the $\mathrm{D}_{\mathrm{h}}$ calculated from TEM images shown in Figure 3 and Table 2. The EXTEM ${ }^{\mathrm{TM}}$ polymer coils in ionic liquid solutions were imaged by TEM, after deposition on TEM grids coated with carbon films. They are shown in Figure 3.

Table 2. Critical concentration $\left(C^{*}\right)$ and the radius of gyration $\left(R_{g}\right)$ calculated from $[\eta]$ of all diluted polymer solutions and TEM.

\begin{tabular}{lcccccc}
\hline $\begin{array}{l}\text { EXTEM }^{T M} / \\
\text { solvents }\end{array}$ & {$[\eta]$} & $C^{* a}$ & $R_{g}{ }^{a}$ & $D_{h}{ }^{a}$ & $D_{h}{ }^{b}$ & $\rho^{c}$ \\
\hline$[$ EMIM]SCN & 18.5 & 0.054 & 9 & 22 & 18 & 1.1181 \\
{$[$ EMIM]OAc } & 39.9 & 0.025 & 11 & 29 & 31 & 1.0992 \\
{$[$ BMIM]SCN } & 52.5 & 0.019 & 12 & 32 & 47 & 1.0707 \\
DMF & 33.7 & 0.030 & 11 & 27 & - & 0.9474 \\
\hline
\end{tabular}

${ }^{a}$ Estimated from viscosity measurements; ${ }^{b}$ Estimated from TEM images; ${ }^{\mathrm{C}}$ Measured at room temperature $\left(22 \pm 1^{\circ} \mathrm{C}\right) ;[\eta]\left(\mathrm{cm}^{3} \mathrm{~g}^{-1}\right)$, $C^{*}\left(\mathrm{~g} \mathrm{~cm}^{-3}\right), R(\mathrm{~nm}), D(\mathrm{~nm})$, and solvent density $\left(\rho, \mathrm{g} \mathrm{cm}^{-3}\right)$

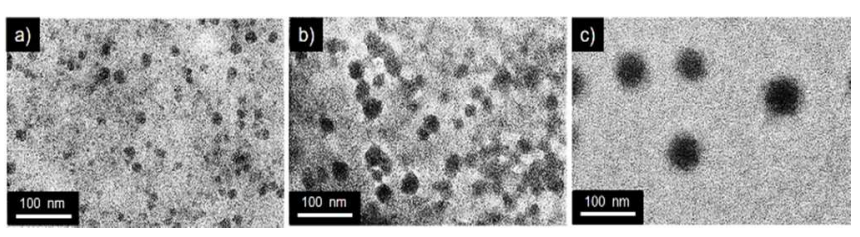

Figure 3. TEM of diluted EXTEMTM polymer coils $(0.1 \mathrm{wt} \%)$ in different ionic liquids: (a) [EMIM]SCN, (b) [EMIM]OAc, and (c) [BMIM] SCN.

\subsection{Rheology of semi-diluted polymer solutions}

The viscoelastic properties of all EXTEM ${ }^{\mathrm{TM}}$ solutions were studied and illustrated in Figure 4. To fabricate membranes and understand the membrane structure, the viscoelastic properties are important, especially for semi-crystalline polymers, such as EXTEM ${ }^{\mathrm{TM}}$. X-ray diffraction (XRD) in Figure 1S shows a strong crystalline peak at 21.5 degrees. Figure $4 \mathbf{a}$ shows that $20 \mathrm{wt} \%$ EXTEM $^{\mathrm{TM}}$ solutions in [EMIM]SCN and [EMIM]OAc have the highest viscosities. When the total viscosity is normalized by the solvent one $\left(\eta / \eta_{0}\right)$ as shown in Figure $4 \mathbf{b}$, we see that the main contribution to the high viscosity of the EXTEM ${ }^{\mathrm{TM}}$ solution in [EMIM]OAc is the solvent viscosity itself. For the $20 \mathrm{wt}^{\%}$ EXTEM $^{\mathrm{TM}}$ solution in [EMIM]SCN the reason for the high viscosity is different, since after the normalization it remains high. The main contribution comes from the poor interaction between EXTEM ${ }^{\mathrm{TM}}$ segments and [EMIM]SCN. From the investigated systems, [EMIM]SCN is the worse solvent, confirmed by the lowest intrinsic viscosity and lowest $\mathrm{R}_{\mathrm{g}}$. While the solvent polymer interaction is poor, the friction between polymer-polymer segments is high. In an entangled system $\left(\mathrm{c}>C^{*}\right)$ this leads to high viscosity with the system behaving like a gel with high storage modulus, as shown in Figure 4c. Solutions in DMF have low viscosity and low storage modulus. Figure 4d plots $\tan (\delta)$ as a function of temperature. $\tan (\delta)$ corresponds to the ratio between the loss and storage moduli. Low $\tan (\delta)$ indicates high elasticity, confirming once again the gel-like behavior of solutions in [EMIM]SCN. Solutions in [BMIM]SCN have the lowest elasticity. This is the best solvent, among those investigated for EXTEM ${ }^{\mathrm{TM}}$, according to $[\eta]$ values. 20 wt $\%$ solutions in [BMIM]SCN are far above $C^{*}$, being highly entangled systems. But in opposite to the case of [EMIM]SCN, the solvent acts as a lubricant between polymerpolymer segments, substantially reducing the friction, increasing the mobility and leading to a liquid-like behavior.

\subsection{Ternary Phase diagram}

The phase diagrams of different EXTEM ${ }^{\mathrm{TM}} /$ solvent/water systems in Figure 5 were obtained by measuring their cloud points. The two-phases region of the diagram increases in the following order: EXTEM $^{\mathrm{TM}} /[\mathrm{EMIM}] \mathrm{OAc}<$ EXTEM $^{\mathrm{TM}} /[\mathrm{BMIM}] \mathrm{SCN} \approx$ EXTEM $^{\mathrm{TM}} / \mathrm{DMF}<$ EXTEM $^{\mathrm{TM}} /[\mathrm{EMIM}] \mathrm{SCN}$. The marked points were obtained by adding water until the turbidity starts. The cloud points for the EXTEM $^{\mathrm{TM}} /[\mathrm{EMIM}] \mathrm{OAc}$ system were hardly detected, due to low turbidity.

The values of $[\eta]$ and $D_{h}$ for binary EXTEM ${ }^{\mathrm{TM}} /$ solvent systems decrease in the following order: EXTEM ${ }^{\mathrm{TM}}$ /

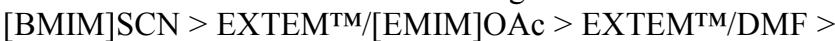
EXTEM $^{\mathrm{TM} /}[\mathrm{EMIM}] \mathrm{SCN}$. This order reflects the decreasing solvent quality. The addition of the non-solvent water destabilizes the solution. It is expected that in an initially better solvent, the solution would sustain larger water addition before reaching the cloud point.

\subsection{Kinetics of phase separation}

The non-solvent induced phase separation of EXTEM ${ }^{\mathrm{TM}}$ casting solutions, which have different viscosity and thermodynamic interactions, was monitored by measuring the relative light transmittance $\left(T_{r}\right)$ as a function of time, as illustrated in Figure 6. The phase separation for membranes prepared from solutions in ionic liquids is slow. The turbidity reaches its maximum only after 40 (EXTEM ${ }^{\mathrm{TM} /[\mathrm{EMIM}] \mathrm{SCN}), \quad 75}$ $\left(\right.$ EXTEM $\left.^{\mathrm{TM}} /[\mathrm{BMIM}] \quad \mathrm{SCN}\right), \quad$ and $55 \quad \mathrm{~s}$ 
$\left(\right.$ EXTEM $\left.^{\mathrm{TM}} /[\mathrm{EMIM}] \mathrm{OAc}\right)$. These systems might stay long in a metastable condition, before separating in two phases. A metastable condition separates the binodal and spinodal curves in a phase diagram estimated from values of Gibbs free energy. On the other hand, the $20 \mathrm{wt} \%$ EXTEM $^{\mathrm{TM}} / \mathrm{DMF}$ system becomes turbid only $3 \mathrm{~s}$ after immersion in water. A fast phase separation, with a fast pathway into the 2 phases region of the phase diagram, normally follows the mechanism of spinodal decomposition (SD). The solutions in ionic liquids probably follow a mechanism of phase separation characterized by nucleation and growth (NG). The conditions for phase separation are a combination of many factors, such as thermodynamic interaction between solvent and non-solvent, polymer and solvent, and between polymer and non-solvent. The mechanism of phase separation is also highly influenced by its kinetics. An important factor in determining the kinetics of phase separation, leading to $\mathrm{SD}$ or NG, might be the solution viscosity. As shown in Figure 4, solutions in ionic liquid have significantly higher viscosity than in DMF. Furthermore, although the viscosity of the system [BMIM]SCN is lower than other ionic liquid based polymer solutions, the phase separation of the system [BMIM]SCN is slightly more delayed than the others. This might be because of the miscibility with water, the non-solvent. The difference in solubility parameters between ionic liquids and water increases in the following order: $[$ EMIM] SCN $<$ [EMIM]OAc $<$ [BMIM]SCN. The lower miscibility and the slightly more hydrophobic properties of [BMIM]SCN delays the solvent-non-solvent exchange and therefore also the phase separation, more than other ionic liquids.
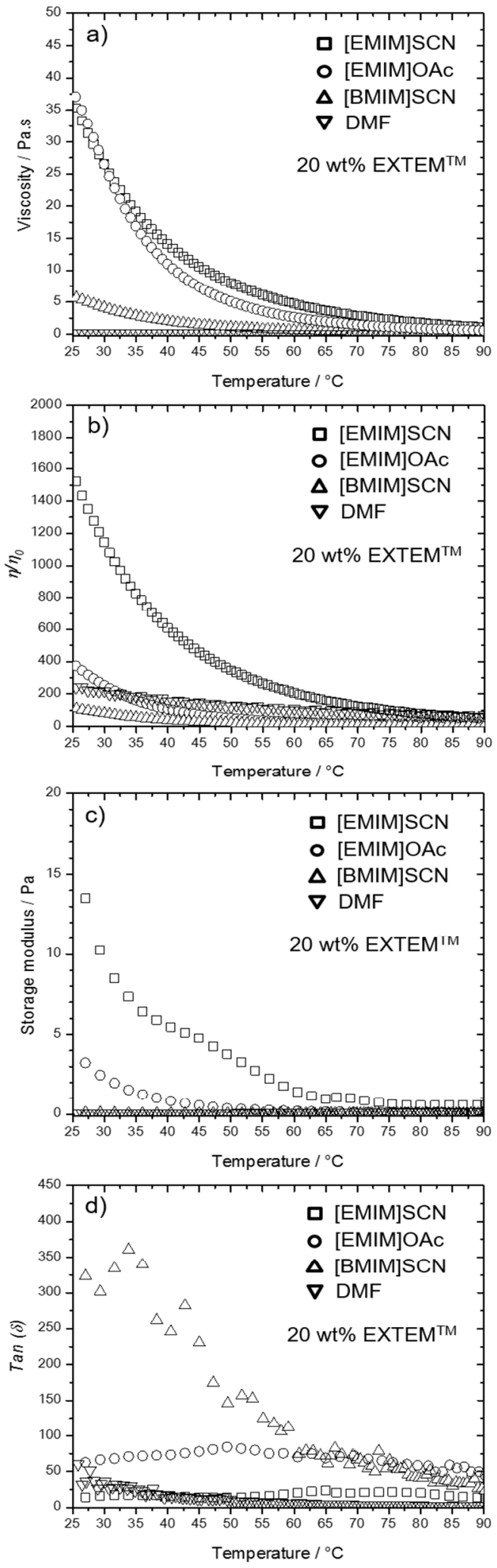

Figure 4. Rheology of $20 \mathrm{wt}^{\mathrm{O}} \mathrm{EXTEM^{ \textrm {TM } }}$ solutions in different solvents as a function of temperature: (a) viscosity at shear rate of $10 \mathrm{~s}^{-1}$, (b) viscosity ratio between solutions and solvents, (c) storage moduli, and (d) $\tan (\delta)$ at shear rate of $20 \mathrm{~s}^{-1}$. 


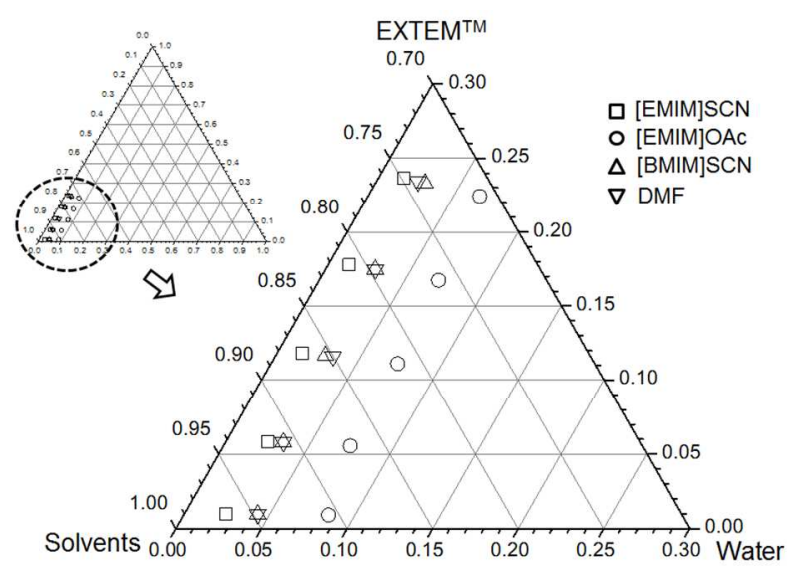

Figure 5. Phase diagram of EXTEMTM solutions using water as a non-solvent at room temperature.

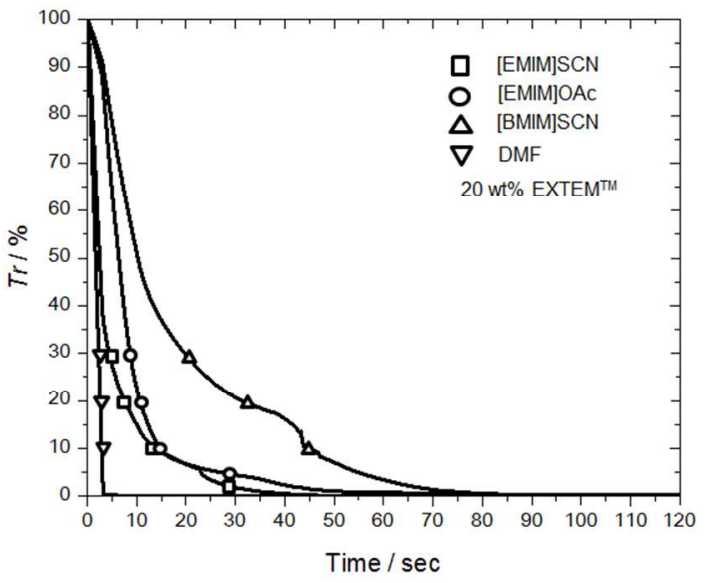

Figure 6. Kinetics of phase separation of EXTEMTM solutions cast on a glass plate and immersed in water.

\subsection{Membrane characterization}

The membranes fabricated from EXTEM ${ }^{\mathrm{TM}} /[\mathrm{EMIM}] \mathrm{SCN}$ solutions have sponge-like structure with fine pores, promoted by the NG mechanism. In contrast, the finger-like cavities can be seen in membranes prepared from solutions in DMF. The cavities resulted from an abrupt water intrusion in the low viscosity polymer solutions. The mean pore size of the membranes prepared from $20 \%$ EXTEM $^{\mathrm{TM}} /[\mathrm{EMIM}] \mathrm{SCN}$ was smaller (approximately $1.5 \mathrm{~nm}$ ) than that of $20 \%$ EXTEM $^{\mathrm{TM}} / \mathrm{DMF}$. Membranes prepared from EXTEM $^{\mathrm{TM}} /[\mathrm{EMIM}] \mathrm{SCN}$ solutions had narrower pore size distribution (Figure 7). The mean pore size was in the nanometer range in all [EMIM]SCN based membranes.

Although EXTEM ${ }^{\text {TM }}$ was also soluble in [EMIM]OAc and [BMIM]SCN and had better thermodynamic interactions than that in [EMIM]SCN, the membranes prepared from these ionic liquids were very brittle with low elasticity (Figure 4). They

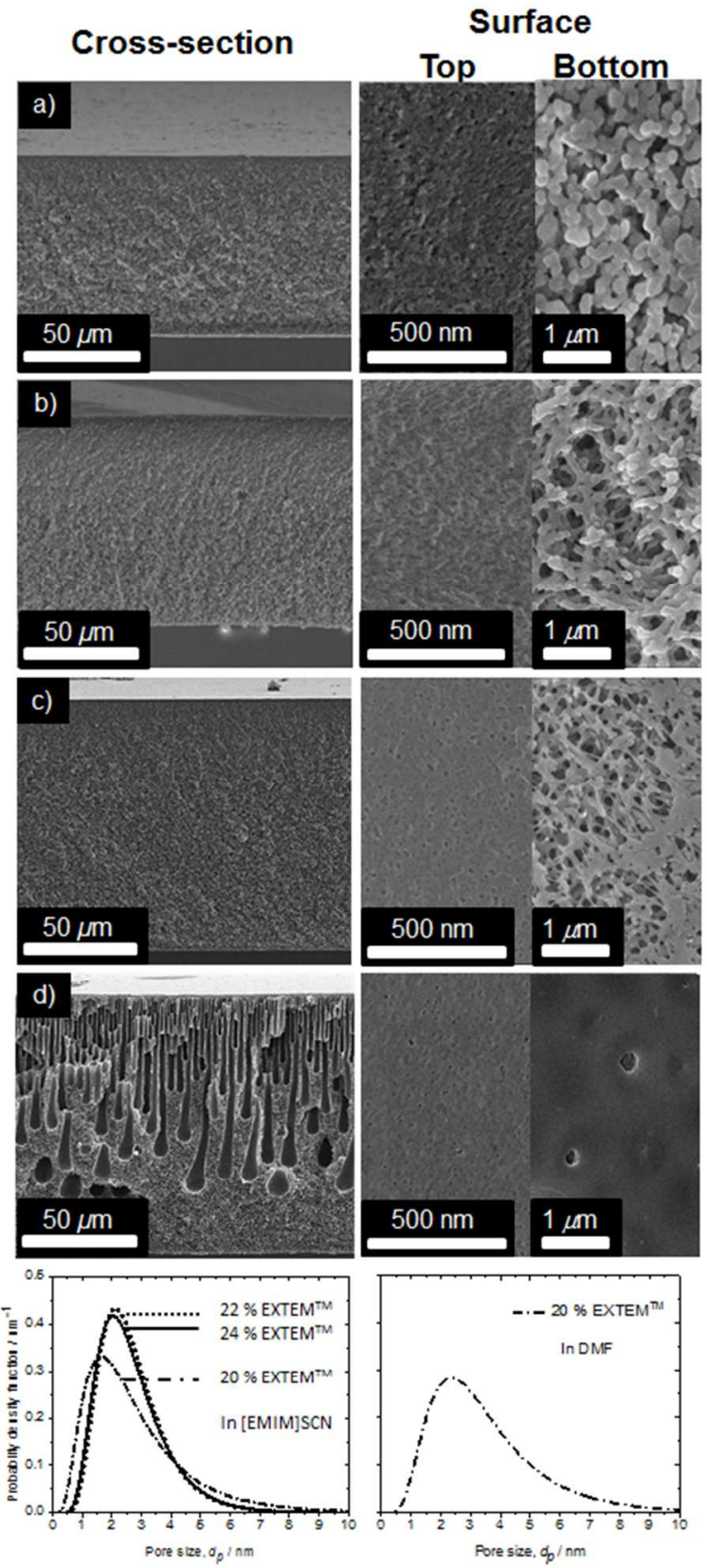

Figure 7. Cross-sectional and surface morphologies cast from the following solutions: (a) $18 \mathrm{wt} \%$ in [BMIM]SCN, (b) 18 wt\% and (c) $20 \mathrm{wt}^{\circ} \mathrm{EXTEM}^{\mathrm{TM}}$ in [EMIM]SCN with pore distributions, and (d) 20 wt\% $^{\text {EXTEM }}{ }^{\mathrm{TM}}$ in DMF with its pore distribution.

were not further characterized in terms of pore size, separation performance and permeance.

All membranes prepared from solutions in [EMIM]SCN have very high water permeance, when compared to those with similar range of pore size, cast from solutions in DMF, as shown in Figure 8. In particular, membranes from $20 \mathrm{wt} \%$ EXTEM $^{\text {TM }}$ solutions in [EMIM]SCN had a permeance of 230 $\mathrm{L} \mathrm{m}^{-2} \mathrm{~h}^{-1}$ bar $^{-1}$, which is $50 \%$ larger than that of membranes prepared from $20 \%$ EXTEM $^{\mathrm{TM}}$ in DMF. 
1

2

3

4

5

6

7

8

9
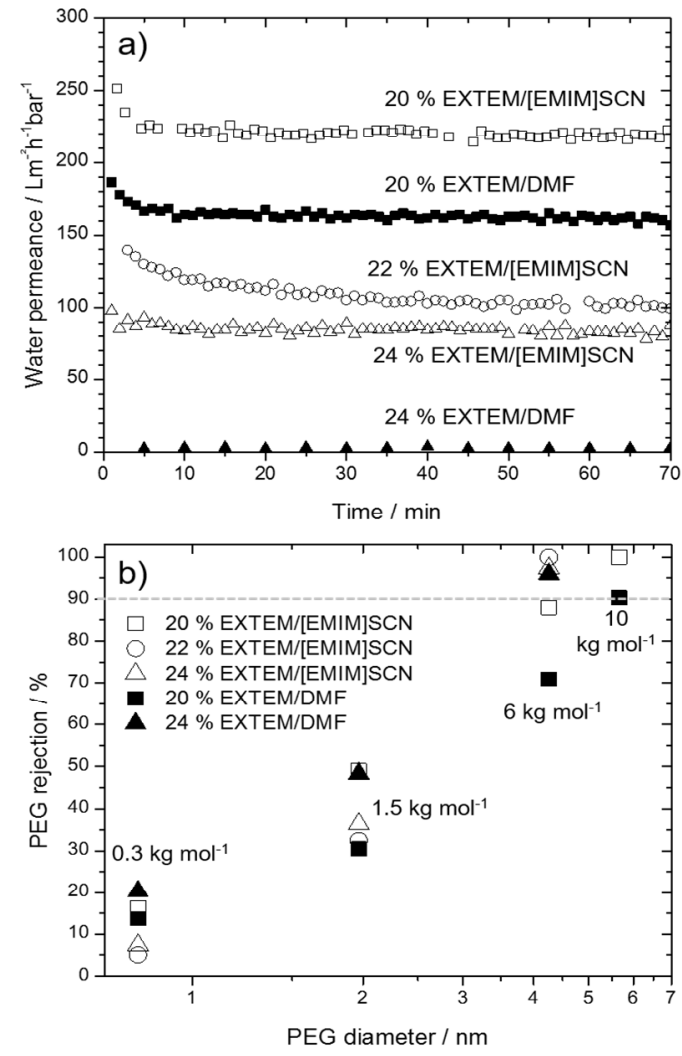

Figure 8. (a) Water permeance and (b) PEG rejection of different membranes.

Table 3. Results of DNA and protein separation

\subsection{DNA and protein separation}

All membranes rejected more than 97 and $99 \%$ of BSA and $\gamma$ globulin, respectively (Table 3). In case of membranes fabricated from 22 and $24 \mathrm{wt} \%$ EXTEM $^{\mathrm{TM}}$ in [EMIM]SCN, they reject DNA up to 84 and $93 \%$ with the molecular weight of $3.4 \mathrm{~kg} \mathrm{~mol}^{-1}$ and 94 and $93 \%$ with the molecular weight of 6.4 $\mathrm{kg} \mathrm{mol}^{-1}$, respectively.

In comparison with membranes cast from solutions of similar polymer concentration, the PEG rejection of the ionic liquid

based membranes was generally higher than that of membranes fabricated from DMF.

3.7. Ionic liquid recovery

The use of ionic liquids as solvents for membrane separation would only be sustainable if recovery and recycling would be possible. Mai et al. ${ }^{51}$ explored various methods such as membrane separation ${ }^{52-54}$ and distillation ${ }^{55-57}$ for ionic liquid recovery with their advantages and disadvantages. In this study, the distillation which is the simplest method, but efficient purification method, was applied with vacuum, heat, and absorption with an absorbent. Waste water of $500 \mathrm{ml}$ after the phase separation was taken from the coagulant bath to recover [EMIM]SCN. We recovered the ionic liquid from the waste after the membrane preparation by 3 steps. First, the initial waste was applied in a rotavapor with the rotation speed of $200 \mathrm{rpm}$, temperature of $80^{\circ} \mathrm{C}$ under the vacuum of $180 \mathrm{mbar}$. Then, further vacuum was applied at $130{ }^{\circ} \mathrm{C}$ for 20 hours. As a last step, magnesium sulfate $\left(\mathrm{MgSO}_{4}\right)$ was added to absorb residual moisture and the recovered ionic liquid was separated from sediments included $\mathrm{MgSO}_{4}$ by centrifugation. The initial concentration of [EMIM]SCN in the bath was $1.6 \%$. After 3 steps of recovery, the final ionic liquid concentration could be increased to $96 \%$ as plotted in Figure 9. The purity of the ionic liquid for casting solution preparation was $\geq 95 \%$. Therefore, it can be fully recovered for reuse.

\begin{tabular}{|c|c|c|c|c|c|}
\hline \multirow{3}{*}{$E X T E M^{\mathrm{TM}}$ in solvents } & \multirow{3}{*}{$\begin{array}{l}M W C O \\
{\left[\mathrm{~kg} \mathrm{~mol}^{-1}\right]}\end{array}$} & \multicolumn{4}{|l|}{ Rejection (\%) } \\
\hline & & $D N A$ & $D N A$ & $B S A$ & $\gamma$-Globulin \\
\hline & & $\left(M_{w}=3.4 \mathrm{~kg} \mathrm{~mol}^{I}\right)$ & $\left(6.4 \mathrm{~kg} \mathrm{~mol}^{-1}\right)$ & $\left(69 \mathrm{~kg} \mathrm{~mol}^{-1}\right)$ & $\left(140 \mathrm{~kg} \mathrm{~mol}^{-1}\right)$ \\
\hline $20 \mathrm{wt} \%$ in [EMIM]SCN & 7.3 & - & - & 97.7 & 99.4 \\
\hline $22 \mathrm{wt} \%$ in $[E M I M] S C N$ & 5.2 & 84.4 & 94.1 & 98.3 & 99.7 \\
\hline $24 \mathrm{wt} \%$ in [EMIM] SCN & 5.3 & 92.7 & 93.1 & 98.1 & 99.2 \\
\hline 20 wt\% in $D M F$ & 9.7 & - & - & 99.7 & 99.4 \\
\hline 24 wt\% in DMF & 5.3 & - & - & 99.7 & 99.4 \\
\hline
\end{tabular}




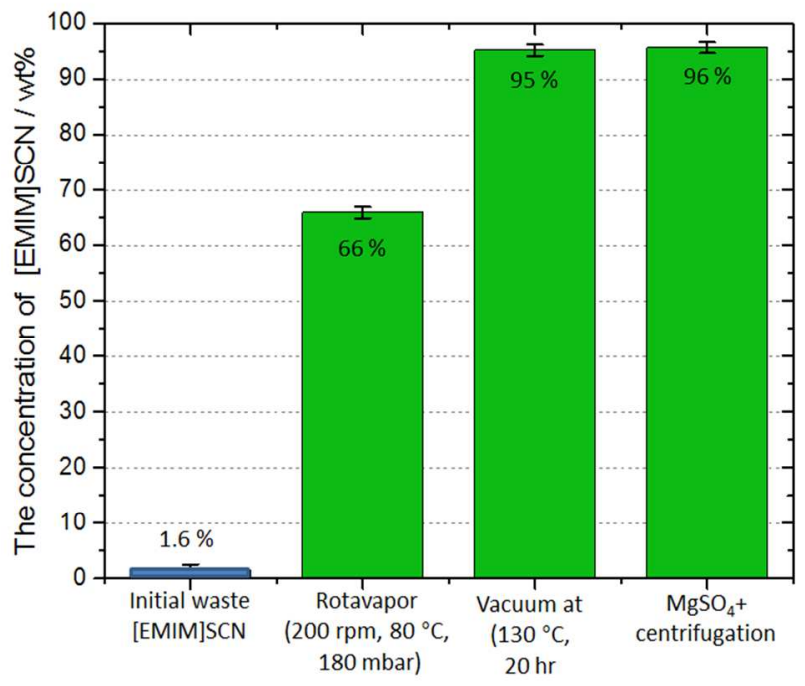

Figure 9. Ionic liquid recovery.

\section{Conclusion}

EXTEM $^{\mathrm{TM}}$ solutions dissolved in pure ionic liquids: [BMIM]SCN, [EMIM]OAc, and [EMIM]SCN. The solutions were examined theoretically and experimentally. Membranes cast from EXTEM ${ }^{\mathrm{TM}}$ solutions in [EMIM]SCN were characterized with the following conclusions:

(1) The order of EXTEM ${ }^{\mathrm{TM}}$ solubility in different solvents is $\mathrm{DMF}>[\mathrm{BMIM}] \mathrm{SCN}>[\mathrm{EMIM}] \mathrm{OAc}>$ [EMIM]SCN, all forming thermodynamically stable solutions.

(2) Membranes cast from EXTEM ${ }^{\mathrm{TM}}$ in $[\mathrm{EMIM}] \mathrm{SCN}$ were mechanically more stable than those cast from [EMIM]OAc and [BMIM]SCN.

(3) $[\eta]$ for EXTEM ${ }^{\mathrm{TM}}$ solutions in different solvents decreased in the following order: [BMIM]SCN > $[$ EMIM]OAc $>$ DMF $>$ [EMIM]SCN.

(4) Membranes cast from EXTEM ${ }^{\mathrm{TM}}$ in [EMIM]SCN have sponge-like structure with narrow pore size distribution and nano-sized pores. In contrast, finger-like cavities were found in the membranes cast from solutions in DMF.

(5) The membranes cast from 20, 22, and $24 \mathrm{wt} \%$ EXTEM $^{\mathrm{TM}}$ solutions in [EMIM]SCN have very high water permeance and higher PEG rejection than those prepared from solutions in DMF. The MWCO values were the following: $7.3 ; 5.2$; and $5.3 \mathrm{~kg} \mathrm{~mol}^{-1}$, respectively. Membranes cast from solutions in [EMIM]SCN rejected BSA and $\gamma$-globulin more than 97 and $99 \%$ and DNA with molecular weight of $6.4 \mathrm{~kg} \mathrm{~mol}^{-1}$ up to 94 and $93 \%$.

(6) Through 3 steps of recovery, the waste [EMIM]SCN after membrane formation was concentrated from 1.6 to $96 \mathrm{wt} \%$ ionic liquid.

\section{Author information}

\section{Corresponding Author}

Suzana P. Nunes*, email: suzana.nunes@kaust.edu.sa

\section{Author Contributions}

The manuscript was written through contributions of all authors.

\section{Acknowledgment}

This work was sponsored by King Abdullah University of Science and Technology (KAUST).

\section{References}

1. Tullis, Richard H.; Duffin, R. P.; Zech， M.; Ambrus, Julian L., Affinity Hemodialysis for Antiviral Therapy. I. Removal of HIV-1 from Cell Culture Supernatants, Plasma, and Blood. Therapeutic Apheresis 2002, 6, (3), 213-220.

2. $\quad$ Samtleben, W.; Dengler, C.; Reinhardt, B.; Nothdurft, A.; Lemke, H.-D., Comparison of the new polyethersulfone high-flux membrane DIAPES ${ }^{\circ}$ HF800 with conventional high-flux membranes during on-line haemodiafiltration. Nephrology Dialysis Transplantation 2003, 18, (11), 2382-2386.

3. Ye, G.; Norihisa, M., Multilayered microfilter using a nanoporous PES membrane and applicable as the dialyzer of a wearable artificial kidney. Journal of Micromechanics and Microengineering 2009, 19, (6), 065031.

4. van Reis, R.; Zydney, A., Bioprocess membrane technology. Journal of Membrane Science 2007, 297, (1-2), 16-50.

5. Al-Sofi, M. A. K.; Hassan, A. M.; Mustafa, G. M.; Dalvi, A. G. I.; Kither, M. N. M., Nanofiltration as a means of achieving higher TBT of $\geq 120^{\circ} \mathrm{C}$ in MSF. Desalination 1998, 118, (1), 123129.

6. Liu, T.-Y.; Zhang, R.-X.; Li, Q.; Van der Bruggen, B.; Wang, X.-L., Fabrication of a novel dual-layer (PES/PVDF) hollow fiber ultrafiltration membrane for wastewater treatment. Journal of Membrane Science 2014, 472, 119-132.

7. Mehta, G. D.; Loeb, S., Performance of permasep B-9 and B-10 membranes in various osmotic regions and at high osmotic pressures. Journal of Membrane Science 1978, 4, 335-349.

8. Mehta, G. D.; Loeb, S., Internal polarization in the porous substructure of a semipermeable membrane under pressure-retarded osmosis. Journal of Membrane Science 1978, 4, 261-265.

9. Peinemann, K. V.; Nunes, S. P.; Wiley, I. Membranes for energy conversion. http://public.eblib.com/choice/publicfullrecord. asp $x$ p $=481734$

10. Giorno, E. D. a. L., Encyclopedia of Membranes. 1 ed.; Springer-Verlag Berlin Heidelberg: Springer-Verlag Berlin Heidelberg, 2016; p XL, 2090.

11. Alberto Figoli, A. C., Sustainable Membrane Technology for Water and Wastewater Treatment. 2017.

12. Lively, R. P.; Sholl, D. S., From water to organics in membrane separations. Nature Materials 2017, 16, 276

13. Koros, W. J.; Zhang, C., Materials for next-generation molecularly selective synthetic membranes. Nature Materials 2017 , 16,289

14. Park, H. B.; Kamcev, J.; Robeson, L. M.; Elimelech, M.; Freeman, B. D., Maximizing the right stuff: The trade-off between membrane permeability and selectivity. Science 2017, 356, (6343).

15. Szekely, G.; Jimenez-Solomon, M. F.; Marchetti, P.; Kim, J. F.; Livingston, A. G., Sustainability assessment of organic solvent nanofiltration: from fabrication to application. Green Chemistry 2014, $16,(10), 4440-4473$.

16. Henderson, R. K.; Jimenez-Gonzalez, C.; Constable, D. J. C.; Alston, S. R.; Inglis, G. G. A.; Fisher, G.; Sherwood, J.; Binks, S. P.; Curzons, A. D., Expanding GSK's solvent selection guide embedding sustainability into solvent selection starting at medicinal chemistry. Green Chemistry 2011, 13, (4), 854-862. 
17. Alfonsi, K.; Colberg, J.; Dunn, P. J.; Fevig, T.; Jennings, S.; Johnson, T. A.; Kleine, H. P.; Knight, C.; Nagy, M. A.; Perry, D. A.; Stefaniak, M., Green chemistry tools to influence a medicinal chemistry and research chemistry based organisation. Green Chemistry 2008, 10, (1), 31-36.

18. Capello, C.; Fischer, U.; Hungerbuhler, K., What is a green solvent? A comprehensive framework for the environmental assessment of solvents. Green Chemistry 2007, 9, (9), 927-934.

19. Ali Mohammad, I., Green Solvents I: Properties and Applications in Chemistry. 2012.

$20 . \quad$ Rogers, R. D.; Seddon, K. R., Ionic Liquids--Solvents of the Future? Science 2003, 302, (5646), 792-793.

21. Swatloski, R. P.; Spear, S. K.; Holbrey, J. D.; Rogers, R. D., Dissolution of Cellose with Ionic Liquids. Journal of the American Chemical Society 2002, 124, (18), 4974-4975.

22. Wang, H.; Gurau, G.; Rogers, R. D., Ionic liquid processing of cellulose. Chemical Society Reviews 2012, 41, (4), 1519-1537.

23. Clough, M. T.; Geyer, K.; Hunt, P. A.; Son, S.; Vagt, U.; Welton, T., Ionic liquids: not always innocent solvents for cellulose. Green Chemistry 2015, 17, (1), 231-243.

24. Takegawa, A.; Murakami, M.-a.; Kaneko, Y.; Kadokawa, J.-i., Preparation of chitin/cellulose composite gels and films with ionic liquids. Carbohydrate Polymers 2010, 79, (1), 85-90.

25. Livazovic, S.; Li, Z.; Behzad, A. R.; Peinemann, K. V.; Nunes, S. P., Cellulose multilayer membranes manufacture with ionic liquid. Journal of Membrane Science 2015, 490, 282-293.

26. Xing, D. Y.; Peng, N.; Chung, T.-S., Investigation of unique interactions between cellulose acetate and ionic liquid [EMIM]SCN, and their influences on hollow fiber ultrafiltration membranes. Journal of Membrane Science 2011, 380, (1-2), 87-97.

27. Kim, D.; Le, N. L.; Nunes, S. P., The effects of a cosolvent on fabrication of cellulose acetate membranes from solutions in 1-ethyl-3-methylimidazolium acetate. Journal of Membrane Science 2016, 520, 540-549.

28. Kim, D.; Salazar, O. R.; Nunes, S. P., Membrane manufacture for peptide separation. Green Chemistry 2016.

29. Xing, D. Y.; Chan, S. Y.; Chung, T.-S., Molecular interactions between polybenzimidazole and [EMIM]OAc, and derived ultrafiltration membranes for protein separation. Green Chemistry 2012, 14, (5), 1405-1412.

30. Madhavan, P.; Sougrat, R.; Behzad, A. R.; Peinemann, K.V.; Nunes, S. P., Ionic liquids as self-assembly guide for the formation of nanostructured block copolymer membranes. Journal of Membrane Science 2015, 492, 568-577.

31. Kim, D.; Moreno, N.; Nunes, S. P., Fabrication of polyacrylonitrile hollow fiber membranes from ionic liquid solutions. Polymer Chemistry 2016, 7, (1), 113-124.

32. Xia, J.; Liu, S.; Pallathadka, P. K.; Chng, M. L.; Chung, T.S., Structural Determination of Extem XH 1015 and Its Gas Permeability Comparison with Polysulfone and Ultem via Molecular Simulation. Industrial \& Engineering Chemistry Research 2010, 49, (23), 12014-12021.

33. Peng, N.; Chung, T.-S.; Chng, M. L.; Aw, W., Evolution of ultra-thin dense-selective layer from single-layer to dual-layer hollow fibers using novel Extem ${ }^{\circledR}$ polyetherimide for gas separation. Journal of Membrane Science 2010, 360, (1-2), 48-57.

34. Jalal, T. A.; Charry Prada, I. D.; Tayouo, R.; Giannelis, E. P.; Nunes, S. P., Reactive phase inversion for manufacture of asymmetric poly (ether imide sulfone) membranes. Reactive and Functional Polymers 2014, 85, 1-10.

35. Mazinani, S.; Darvishmanesh, S.; Ehsanzadeh, A.; Van der Bruggen, B., Phase separation analysis of Extem/solvent/non-solvent systems and relation with membrane morphology. Journal of Membrane Science 2017, 526, 301-314.

36. Kim, D.; Moreno, N.; Nunes, S. P., Fabrication of polyacrylonitrile hollow fiber membranes from ionic liquid solutions. Polymer Chemistry 2016.

37. Rubinstein, M.; Colby, R. H., Polymer Physics. OUP Oxford: 2003.
38. Lindvig, T.; Michelsen, M. L.; Kontogeorgis, G. M., A Flory-Huggins model based on the Hansen solubility parameters. Fluid Phase Equilibria 2002, 203, (1-2), 247-260.

39. Mark, J. E., -, Physical properties of polymers handbook. Array ed.; Springer: New York, 2007.

40. Hansen, C. M., Hansen solubility parameters: a user's handbook. CRC Press LLC: N.W., Boca Raton, Florida 33431., 2000. 41. Biroa, J.; Zeman, L.; Patterson, D., Prediction of the $\mathrm{x}$ Parameter by the Solubility Parameter and Corresponding States Theories. Macromolecules 1971, 4, (1), 30-35.

42. Kilaru, P. K.; Scovazzo, P., Correlations of low-pressure carbon dioxide and hydrocarbon solubilities in imidazolium-, phosphonium-, and ammonium-based room-temperature ionic liquids. Part 2. Using activation energy of viscosity. Industrial \& Engineering Chemistry Research 2008, 47, (3), 910-919.

43. Weerachanchai, P.; Chen, Z.; Leong, S. S. J.; Chang, M. W.; Lee, J.-M., Hildebrand solubility parameters of ionic liquids: Effects of ionic liquid type, temperature and DMA fraction in ionic liquid. Chemical engineering journal 2012, 213, 356-362.

44. Xing, D. Y.; Peng, N.; Chung, T.-S., Formation of cellulose acetate membranes via phase inversion using ionic liquid,[BMIM] SCN, as the solvent. Industrial \& Engineering Chemistry Research 2010, 49, (18), 8761-8769.

45. Xing, D. Y.; Peng, N.; Chung, T.-S., Investigation of unique interactions between cellulose acetate and ionic liquid [EMIM] SCN, and their influences on hollow fiber ultrafiltration membranes. Journal of Membrane Science 2011, 380, (1), 87-97.

46. Derecskei, B.; Derecskei-Kovacs, A., Molecular modelling simulations to predict density and solubility parameters of ionic liquids. Molecular Simulation 2008, 34, (10-15), 1167-1175.

47. Kok, C. M.; Rudin, A., Relationship between the hydrodynamic radius and the radius of gyration of a polymer in solution. Die Makromolekulare Chemie, Rapid Communications 1981, 2, (11), 655-659.

48. Rahimpour, A.; Madaeni, S. S.; Mansourpanah, Y., Nanoporous polyethersulfone (PES) membranes modified by acrylic acid (AA) and 2-hydroxyethylmethacrylate (HEMA) as additives in the gelation media. Journal of Membrane Science 2010, 364, (1-2), 380388.

49. Singh, S.; Khulbe, K. C.; Matsuura, T.; Ramamurthy, P., Membrane characterization by solute transport and atomic force microscopy. Journal of Membrane Science 1998, 142, (1), 111-127.

50. Nguyen, Q. T.; Neel, J., Characterization of ultrafiltration membranes. : Part IV. Influence of the deformation of macromolecular solutes on the transport through ultrafiltration membranes. Journal of Membrane Science 1983, 14, (2), 111-127.

51. Mai, N. L.; Ahn, K.; Koo, Y.-M., Methods for recovery of ionic liquids-A review. Process Biochemistry 2014, 49, (5), 872881 .

52. Haerens, K.; Van Deuren, S.; Matthijs, E.; Van der Bruggen, B., Challenges for recycling ionic liquids by using pressure driven membrane processes. Green Chemistry 2010, 12, (12), 21822188.

53. Kröckel, J.; Kragl, U., Nanofiltration for the Separation of Nonvolatile Products from Solutions Containing Ionic Liquids. Chemical Engineering \& Technology 2003, 26, (11), 1166-1168.

54. Abels, C.; Redepenning, C.; Moll, A.; Melin, T.; Wessling, M., Simple purification of ionic liquid solvents by nanofiltration in biorefining of lignocellulosic substrates. Journal of Membrane Science 2012, 405-406, 1-10.

55. Huang, K.; Wu, R.; Cao, Y.; Li, H.; Wang, J., Recycling and Reuse of Ionic Liquid in Homogeneous Cellulose Acetylation. Chinese Journal of Chemical Engineering 2013, 21, (5), 577-584.

56. Xing, D. Y.; Peng, N.; Chung, T.-S., Formation of Cellulose Acetate Membranes via Phase Inversion Using Ionic Liquid, [BMIM]SCN, As the Solvent. Industrial \& Engineering Chemistry Research 2010, 49, (18), 8761-8769.

57. Kim, D.; Vovusha, H.; Schwingenschlögl, U.; Nunes, S. P., Polyethersulfone flat sheet and hollow fiber membranes from solutions in ionic liquids. Journal of Membrane Science 2017, 539, (Supplement C), 161-171. 
55

56

57

58

59 


\section{Table of Contents and Abstract Graphics}

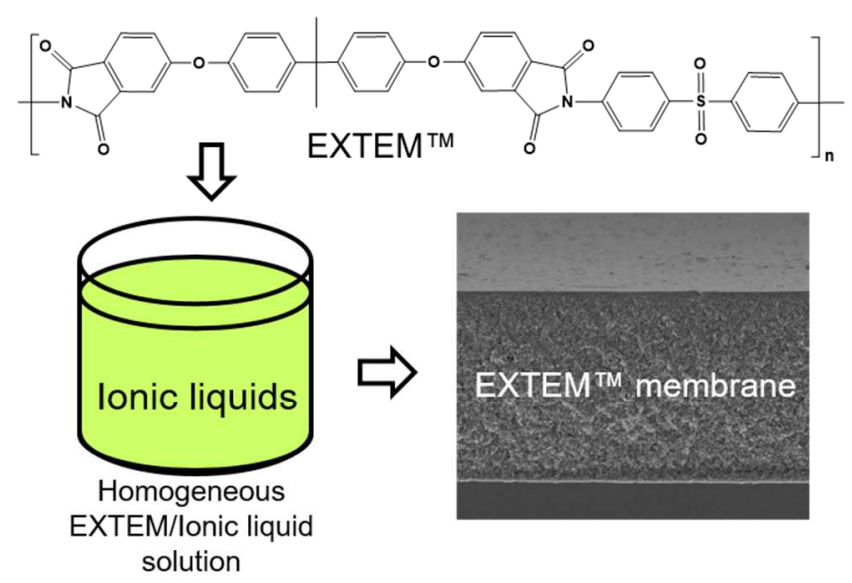

